\title{
Quem escreve a História da Educação? José Ricardo Pires de Almeida e o lugar da narrativa
}

\author{
Who writes the History of Education? José Ricardo Pires de Almeida and the place of \\ the narrative
}

RESUMO:

Rosimar Serena Siqueira Esquinsani ${ }^{1}$

O texto examina a versão, em português, da obra L'Instruction publique au Brésil: histoire et legislation (1500-1889), de José Ricardo Pires de Almeida, evidenciando suas tendências interpretativas ao considerá-la como um importante registro pioneiro da história da educação nacional. Assim, o texto apresenta resultados de uma pesquisa de base bibliográfica, pautada por uma metodologia analítico-reconstrutiva, cujo escopo incide sobre contribuições ao debate acerca de historiadores e da historiografia da educação brasileira. A obra, em questão, foi examinada a partir do procedimento da análise de conteúdo, utilizando-se a técnica da análise temática. O artigo organiza-se a partir de dois momentos: a) a contextualização da obra e; b) cinco abordagens evidenciadas pelo autor através de sua obra: o tom ufanista; a perspectiva imperial ou sua aderência a monarquia; o dualismo escolar presente na narrativa; a perspectiva de história comparada e, por fim, as contribuições da obra para a história da educação brasileira. Concluímos que, apesar do compromisso assumido pelo historiador/autor em relevo com o seu lugar de fala, a obra tem méritos evidentes e, o maior de todos, sistematiza informações acerca da história da educação brasileira, fato pioneiro no período e na abrangência da narrativa.

Palavras-chave: História da Educação. Historiador da educação. Historiografia.

\begin{abstract}
:
The text examines the portuguese version of the book L'Instruction publique au Brésil: histoire et legislation (1500-1889), from José Ricardo Pires de Almeida, evidencing its interpretative tendencies, and considering it as an important pioneering record in the history of national education. Thus, the text presents the results of a literature-based research, based on an analytical-reconstructive methodology, whose scope focuses on contributions to the debate about historians and the historiography of Brazilian education. The work in question was examined from the content analysis procedure, using the thematic analysis technique. The article is organized from two moments: a) the contextualization of the work and, b) five approaches evidenced by the author through his work: the tone of the artist; the imperial perspective or its adherence to the monarchy; the school dualism present in the narrative; the perspective of comparative history and, finally, the contributions of the work to the history of Brazilian education. We conclude that despite the commitment of the historian / author in relief with his place of speech, the work has clear merits and, the greatest of all, systematizes information about the history of Brazilian education, a pioneering fact in the period and the comprehension of the narrative.
\end{abstract}

Keywords: History of Education. Historian of education. Historiography.

\footnotetext{
${ }^{1}$ Pós-Doutora e Doutora em Educação pela Universidade Vale do Rio dos Sinos (UNISINOS); Professora titular da Universidade de Passo Fundo (UPF).
}

Recebido em outubro de 2017/ Aprovado em janeiro de 2018 
A tarefa de elaborar narrativas históricas nem sempre coube ao historiador de formação acadêmica. Intérpretes de distintas formações, eventualmente, se consideram aptos a desenvolver narrativas e a ocupar-se do ofício de historiador (BLOCH, 2001). Alexis de Tocqueville - 1805 a 1859; Pierre Villar - 1906 a 2003; Leopoldo Von Ranke - 1795 a 1896; só para citar alguns exemplos internacionais, não eram historiadores de formação. Dois dos mais importantes historiadores brasileiros, Gilberto Freyre (19001987) e Sérgio Buarque de Hollanda (1902-1982), também não eram formados academicamente em história.

Na história da educação, seja por seu estatuto híbrido (NÓVOA, 2004; FELGUEIRAS, 2008), dividido entre a história e a pedagogia, ora seguindo a linha da história, ora seguindo os temas relevantes e pontuais da educação. Por ter assumido involuntariamente um "lugar de ciência auxiliar da Pedagogia" (VIDAL; FARIA FILHO, 2003, p.51), a presença de intérpretes com diferentes formações figura como legítima e, vez por outra, pauta o relato historiográfico.

Esse é o caso do médico José Ricardo Pires de Almeida (07 de dezembro de 1843 - 24 de setembro de 1913), historiador por prática e não por formação acadêmica, autor "daquela que é considerada a primeira história sistematizada da educação brasileira” (SAVIANI, 2009, p. 236), o livro L'Instruction publique au Brésil: histoire et legislation (1500-1889), publicado pela primeira vez, em 1889.

Escrito em francês, pois de acordo com o autor tratava-se de uma "língua universalmente conhecida" (ALMEIDA, 2000, p. 17) a obra foi disponibilizada em português apenas em 1989 - no centenário de sua publicação original -, fazendo parte da série Memória da Educação brasileira, em uma edição conjunta do INEP (Instituto Nacional de Estudos e Pesquisas Educacionais) e da PUC/SP (Pontifícia Universidade Católica de São Paulo).

José Ricardo Pires de Almeida também era monarquista declarado, posição que pauta boa parte da condução de sua obra, inclusive na escolha do enfoque temporal, que prioriza os temas educacionais do Brasil Imperial em relação aos outros momentos históricos. Com uma dedicatória dirigida ao conde D'Eu (Luís Filipe Maria Fernando Gastão de Orléans - 1842 - 1922)

o livro [...] discorria particularmente sobre a educação no pós-Independência. A época colonial era abordada apenas na Introdução ao volume, indiciando sua pequena relevância, apesar de nela se inscrever o esforço precursor dos jesuítas, sumariamente descrito nas cinco páginas iniciais; as iniciativas pombalinas, narradas nas dez páginas seguintes; e o evento fundador da 
educação no Brasil, a chegada de D. João VI (VIDAL; FARIA FILHO, 2003, p. 40, grifos nossos).

Outro ponto característico presente na obra diz respeito às linhas narrativas deliberadamente assumidas pelo autor que, de um lado utiliza o tom exageradamente ufanista em relação aos progressos brasileiros no campo da educação e, de outro lado, flerta com as comparações entre realidades, principalmente ao enaltecer os avanços da educação brasileira em contraposição à educação sul-americana, sobretudo em relação à educação na Argentina.

Todavia o livro - à despeito de sua questionável abordagem interpretativa da realidade educacional brasileira -, é pioneiro ao sistematizar a educação nacional, pois:

O escrito é um testemunho importante de diversas questões: a legislação educacional; o financiamento da educação pública; a distribuição das matrículas por sexo, nacionalidade e condição social; as condições de exercício da profissão docente; a organização e a função das escolas primárias e secundárias; o ensino superior nas faculdades de direito, medicina e engenharia, o debate parlamentar em torno da criação de uma universidade no país; a estruturação do ensino normal e profissional; a educação feminina; a adoção do método de ensino mútuo; além de informações sobre bibliotecas, academias científicas, centros de cultura e beneficência presentes no cenário do Segundo Reinado (VIEIRA, 2015, p.754).

Assim, por seu caráter de registro, a obra de José Ricardo Pires de Almeida autoriza "uma reflexão acerca da historiografia da educação brasileira ao ser tomado como objeto por intermédio do qual se pode discutir a ordem que possibilitou o seu aparecimento, bem como a ordem que o mesmo procura instaurar" (GONDRA, 2000, p.189).

Porém, ainda que assumindo o caráter de registro da obra de Almeida, estamos atentos ao seu lugar de produção, pois, conforme assevera Gondra, o livro

trata-se [...], de uma peça de propaganda do regime imperial escrita de um determinado lugar (o da elite branca e letrada), para outra elite (leitora de francês), isto é, para poucos leitores, uma vez que os índices de analfabetismo da população em geral eram superiores a $80 \%$. Dentre os alfabetizados, deduzimos que o número de leitores em francês deveria ser, certamente, ainda bem menor. [...] Aqui se percebe que o discurso registrado pelo autor (e do autor) é o discurso da ordem vigente. Um discurso marcado pela divulgação dos fatos e homens do Império em seus grandes esforços para civilizar e construir o Estado pelo viés da instrução. O discurso do autor procura representar, assim, o discurso do Estado Imperial. É a voz do dono (do Estado) registrada pelo dono da voz (aqueles que estão autorizados a registrá-la). Uma voz ecoa na outra e toma a forma de escrita. Assim sendo, contribui para reforçar a ordem monárquica (GONDRA, 2003, p. 646). 
Desta feita, o texto apresenta resultados de uma pesquisa de base bibliográfica, pautada por uma metodologia analítico-reconstrutiva, cujo escopo incide sobre contribuições ao debate acerca de historiadores e da historiografia da educação brasileira, a partir dos recursos advindos da pesquisa científica, compreendendo a historiografia como "a própria ciência histórica é colocada numa perspectiva histórica com o desenvolvimento da historiografia, ou história da história" (LE GOFF 2003, p. 12). Assim sendo, a historiografia da educação nada mais é do que o estudo da história da história da educação.

A obra em questão foi eleita para exame a partir do critério da representatividade (BARDIN, 2007) e considerada a partir do procedimento da análise de conteúdo, utilizando-se a técnica da análise temática, em que o "[...] tema é a unidade de significação que se liberta naturalmente de um texto analisado, segundo critérios relativos à teoria que serve de guia à leitura" (BARDIN, 2007, p.105).

Também foram seguidos os passos descritos por Bardin (2007) como componentes de um procedimento de análise de conteúdo: 1) pré-análise (ou escolha e organização do corpus documental); 2) descrição analítica (investigação sobre o material); e 3) comentários inferenciais.

Empenhado em traduzir diálogos entre a história da educação e a história como ciência, o artigo procura ainda reivindicar um espaço para a discussão da história da educação a partir das abordagens dos sujeitos ocupados com o ofício de historiador:

\footnotetext{
o historiador é um ser no mundo com compromissos que historicamente lhe são inerentes. E esta vinculação com a realidade que o faz mergulhar no passado par a melhor compreender o presente. Esta vinculação não deve ser algo perfunctório, mas sim o amálgama essencial que conduz a escolha da teoria e da opção metodológica. Está inserida aqui a ideia de que em cada investigação existe um projeto de transformação para a sociedade. A pesquisa deve responder a algo, e este algo deve ser socialmente construído. Aqui aparece novamente o compromisso social do pesquisador e os valores que lhe são constitutivos (TAMBARA, 2000, p. 81).
}

Por fim, cabe destacar que o texto apresentado é parte integrante de um contexto amplo de pesquisa, que objetiva contribuir para a discussão da educação em redes e sistemas públicos de ensino, enquanto pauta candente na composição da agenda educacional. 


\title{
A produção da história da educação...
}

O objeto da pesquisa, que resultou no presente texto, consiste na produção de interpretações da história, realizada por José Ricardo Pires de Almeida, enquanto historiador de ofício que narra ou conta parte da história da educação brasileira. Nessa direção, à história da educação brasileira ainda cabem marcos e amarras teóricas que aprofundem a epistemologia própria do campo, posto que

\begin{abstract}
Se entendermos campo como uma área profissional de interesse comum, cujos membros assumem certa consciência de seu pertencimento a essa área, têm afinidades entre si e se organizam em torno de objetivos comuns, podemos considerar que a organização da história da educação como um campo específico é fenômeno relativamente recente (SAVIANI, 2009, p. 235)
\end{abstract}

Essa característica da história da educação ser um campo relativamente recente abre possibilidades para o flerte intencional e a busca por amparo na historiografia, o que nos auxilia a estipular e estimular com mais vivacidade os horizontes de trabalho, pois o historiador da educação deseja "marcar o seu pertencimento à comunidade dos historiadores e uma maneira de reafirmar a identificação de suas pesquisas com procedimentos próprios ao fazer historiográfico" (VIDAL; FARIA FILHO, 2003, p.60).

Particularmente na produção da história da educação dois pressupostos nos parecem pertinentes: o lugar da produção e os estilos de produção. Ambos os pressupostos são representativos dos elementos de fixação da historiografia da educação em um quadro de referências e análises.

No que concerne ao pressuposto do lugar de produção, comungamos com as palavras de Certeau, uma vez que:

Toda pesquisa historiográfica se articula com um lugar de produção socioeconômico, político e cultural. Implica um meio de elaboração circunscrito por determinações próprias: uma profissão liberal, um posto de observação ou de ensino, uma categoria de letrados, etc. Ela está, pois, submetida a imposições, ligada a privilégios, enraizada em uma particularidade. É em função deste lugar que se instauram os métodos, que se delineia uma topografia de interesses, que os documentos e as questões, que lhes serão propostas, se organizam (CERTEAU, 2011, p.47).

Assim, um historiador compõe sua narrativa a partir de um lugar de observação, de um lugar de registro e, portanto, de um lugar de produção e de argumentos. Não há narrativa no vazio de espaço. Somos frutos dos contextos que nos indexam à observação, registro e produção da história. 
José Ricardo Pires de Almeida assume um lugar de produção muito claro em sua obra. Representa, com afinco, um espaço e um posicionamento que dirigem seu olhar e sua narrativa no decurso de sua obra.

Além do mais - e aqui reside o segundo pressuposto -, toda escrita da história é realizada a partir de estilos presentes ao ofício do historiador (GAY, 1990). Em José Ricardo Pires de Almeida, os estilos explicados por Gay são transbordantes: literário, emocional, profissional e o pensar (GAY, 1990) mas, mais do que isso, são categoricamente coerentes em sua produção, uma vez que "os estilos compõem uma rede de indícios que apontam uns para os outros e somados para o homem" (GAY, 1990, p. 24).

Cientes do estilo entrelaçado e marcante de Almeida e tomando o livro como um documento sendo, pois, "antes de mais nada o resultado de uma montagem, consciente ou inconsciente, da história, da época, de uma sociedade que o produziram" (LE GOFF 2003, p. 547), centramos análises em cinco abordagens evidenciadas pelo autor através de sua obra: o tom ufanista; o ponto de vista imperial ou sua aderência à monarquia; o dualismo escolar presente na narrativa; a perspectiva de história comparada e, por fim, as contribuições da obra de José Ricardo Pires de Almeida para a história da educação brasileira.

\section{Abordagens evidenciadas pelo autor...}

A partir do escopo investigativo proposto, a primeira abordagem que examinaremos diz respeito ao ufanismo exacerbado que transborda em todo o texto de Almeida, ora assegurado pelo tom extremamente elogioso ao período Imperial, em especial à atuação de Dom João VI, ora pelos adjetivos utilizados para enaltecer figuras históricas ligadas ao Império mas, na maior parte do tempo, por ambas as estratégias discursivas.

A própria justificativa apontada pelo autor para a realização de sua obra já deixa evidente a nuança ufanista e de marcada posição ideológica que conduzirá os escritos, pois

a idéia de escrever um livro e publicá-lo numa língua universalmente conhecida [francês] nasceu do legítimo sentimento de orgulho nacional, como também do patriótico desejo de suprir uma sensível lacuna existente nos livros dos escritores que se ocuparam do estado da instrução em diferentes países do globo. Quase todos, com efeito, passaram em silêncio o mais importante, mais vasto, mais rico e populoso estado da América do Sul - o Brasil. Suas obras nos informam exatamente sobre os negócios da instrução pública nos principados de Lippe e de Waldeck e até da Sérvia, mas 
se calam sobre o grande império, cujo soberano é conhecido e estimado pelo mundo inteiro (ALMEIDA, 2000, p. 17, grifos nossos).

O ufanismo escolhido como tom da narrativa está, de sobremaneira, expresso no recorte temporal selecionado para conduzir a narrativa: o Brasil Império, assumido como período de pujança, vigor e progresso da nação. Em razão desse recorte, o texto do autor restou por ser organizado em duas partes que expõem a

instrução pública no Brasil, tanto do ponto de vista histórico quanto do ponto
de vista legislativo, a primeira parte corresponde à época que vai da
declaração de Independência ao Ato Adicional à Constituição. A segunda,
estende-se do Ato Adicional até nossos dias. Entretanto, para maior
comodidade da exposição, esta última parte será subdividida em dois
períodos: 1834 a 1856 e 1856 a 1889 (ALMEIDA, 1898, p.56).

Desse modo há uma segunda abordagem utilizada pelo autor: o ponto de vista imperial ou sua aderência a monarquia. Como bom monarquista, Almeida fazia uma defesa firme do Brasil Imperial, uma vez que o Brasil Colônia "sempre foi hostil ao desenvolvimento da instrução pública e - salvo raras exceções - sempre reprimiu a expansão do espírito nacional" (ALMEIDA, 2000, p.37).

Além da hipotética hostilidade do período colonial para com a instrução pública, outro fator que leva o autor a optar pelo relevo ao período imperial deve-se, aparentemente, à figura de Dom João VI. Presença constante na narrativa, as ações joaninas são, em geral, sublinhadas por uma aura de destaque:

Restringindo-nos à instrução pública somente, recordaremos que o governo de D. João VI, no Brasil, criou, em 1808, no Mosteiro de São Bento, uma Academia de Marinha, destinada à instrução dos jovens que abraçassem a carreira marítima; estabeleceu uma Escola Anatômica, Cirúrgica e de Medicina, em 1809, e fundou diversas escolas em diferentes lugares. Fizeram-se, neste mesmo ano, diversas nomeações de professores de Latim, que eram, geralmente, escolhidos e indicados pelo Clero; o bispo assinava o diploma de sua nomeação e eram instalados pelo Senado da Câmara. Elevouse também o número de mestres encarregados de ensinar a ler, escrever e contar. (ALMEIDA, 2000, p. 41-42).

O sentimento patriótico e ufanista que perpassa toda a obra assevera-se ante a figura de Dom João VI. Aqui o lugar de fala do historiador é crivado pelo sentimento nacionalista e monarquista, que empresta relevância e sentido às observações de Le Goff: "há uma historicidade da história que implica o movimento que liga uma prática interpretativa a uma práxis social" (LE GOFF, 2003, p. 19). A figura de Dom João VI é enaltecida desde o ponto em que, para o autor: 
Sob o governo paternal deste soberano, o brasileiro não se fez mais dependente do português, tornou-se cidadão do reino do Brasil; seu rei era o mesmo que o de Portugal mas seu governo era outro, suas instituições diferentes. Seus funcionários, cada vez mais, tornaram-se unicamente brasileiro. Constatamos esta tendência firmar-se nos assuntos da instrução pública, mas o mesmo acontecia em todos os ramos da administração. (ALMEIDA, 2000, p. 50-51).

José Ricardo Pires de Almeida, ao atribuir a Dom João VI o empenho em fazer prosperar a educação nacional, indica, claramente, sua aderência ao regime monárquico, fazendo de sua obra uma verdadeira ode à monarquia brasileira:

A chegada ao Brasil de S.A.R. o Príncipe Regente de Portugal, mais tarde D. João VI, é o ponto de partida de uma época feliz, porque este augusto soberano, reconhecendo que esta país era a mais preciosa jóia de sua coroa, procurou enaltecê-la, seja criando os tribunais de justiça ou organizando a administração, seja encorajando a instrução pública, compenetrado que estava deste axioma - Saber é poder" (ALMEIDA, 2000, p.50, grifos nossos)

Almeida ainda lança mão de uma terceira abordagem que assume, justifica e fomenta, abertamente, o dualismo escolar. Contudo, prevê saberes mínimos necessários a todos, uma vez que havia "conhecimentos indispensáveis tanto para o pobre quanto para o rico, para o menos inteligente quanto para o mais dotado: saber ler, saber escrever e saber contar. Os camponeses tanto quanto os moradores das cidades precisam destes conhecimentos" (ALMEIDA, 2000, p. 82).

Tomando como documento que "não é qualquer coisa que fica por conta do passado, é um produto da sociedade que o fabricou segundo as relações de forças que aí detinham o poder" (LE GOFF, 2003, p. 535), a obra de Almeida mostra-o como filho de sua época e do contexto histórico no qual estava inserido, deixando registrado suas concepções de classe, mormente quando narra sua visão peculiar sobre as cidades do período, em especial o Rio de Janeiro:

\footnotetext{
Nas cidades em geral e no Rio de Janeiro em particular há dois elementos presentes: uma classe média inteligente e, em geral, voltada para o bem e classes inferiores muito miscigenadas [...] possuindo um fundo hereditário de depravação que transparecerá nas ocasiões de faltas e maus exemplos [...] já se conhece como são os filhos desses pais: pálidos, fracos, mal-nutridos; trazem em seu rosto um descaramento precoce; instintos perversos já se apropriam do coração desses pequenos seres [...] (ALMEIDA, 2000, p.9394).
}

Suas concepções de classe são confessadamente expostas na obra, especialmente quando aponta o possível sinônimo entre o que ele denomina de 'classes inferiores' e 
miscigenação; a depravação como herança que de maneira suposta acometeria tais 'classes inferiores'; além do estigma às crianças filhas dessas classes, que apresentariam um instinto supostamente perverso e cínico desde muito cedo

Ainda em relação às classes sociais vulneráveis, Almeida mostrou-se contundente e parecia referir-se a elas de um ponto de vista crivado por preconceitos de toda a ordem. Sobre a escolarização das classes trabalhadoras, por exemplo, afirmava que

\begin{abstract}
as classes ocupadas com trabalhos manuais ou degradadas pelos hábitos ociosos ou viciosos parecem, em muitos casos, comprazer-se com a ignorância. As escolas são para os pais, desta categoria, apenas um meio de ficarem desobrigados da vigilância de seus filhos [...] Estas criaturas saem muitas vezes da escola tão logo quanto entraram, sem qualquer instrução nem mais moralizados nem menos turbulentos (ALMEIDA, 2000, p.94).
\end{abstract}

Percebe-se, aqui, a matiz fortemente conservadora em relação às classes sociais menos favorecidas e vulneráveis, além de outros três pontos: o autor emparelha trabalhadores manuais a sujeitos em condição de ócio ou vício; faz referência à escola como depósito de crianças para onde os pais "desta categoria" enviariam seus filhos a fim de ficarem livres da sua presença e, por fim, atribui ênfase à escola como lugar de molde moral, onde a criança poderia aprender certa moralização diferente da recebida em seu lar. Interessante perceber que a análise do autor acerca da realidade das classes sócias vulneráveis, bem como da relação destas com a escola, é suficientemente cética e conservadora, porém não chega sequer a ser piedosa.

Uma quarta abordagem destacada na obra de Almeida diz respeito ao constante tom comparativo em razão da posição que ele julga pertencer ao Brasil junto às demais nações da América do Sul, em especial, em relação à Argentina. Com vários dados quantitativos, o autor empenha-se em provar: “1”, que o Brasil não está atrasado em relação à instrução pública; $2^{\circ}$, que chegará logo a ocupar o primeiro plano intelectual entre as nações sul americanas" (ALMEIDA, 2000, p.302).

No decorrer do livro, o autor ressalta sua intenção de empenhar um estudo comparado (ainda que tendenciosamente favorável ao Brasil), carregado de tom patriótico, uma vez que “o Brasil não está atrás de nenhuma nação sul-americana em matéria de ensino público e, em muitos aspectos, nada tem a invejar de outros povos" (ALMEIDA, 2000, p. 22). 
Por óbvio, na concepção de Almeida, esse progresso e emparelhamento do país às demais nações só foi possível com a vinda da Família Real Portuguesa para o Brasil, em 1808, pois

não há brasileiro esclarecido que não admita D. João VI como verdadeiro fundador do Império do Brasil, sob um outro título, é verdade, mas que não diminui em nada o mérito do vigoroso impulso que esta monarquia soube dar à civilização do país. Até D. João VI, o brasileiro não existia, era apenas um português nascido numa colônia; se quisesse instruir-se, chegar a ser alguma coisa, precisava ir a Portugal (ALMEIDA, 2000, p 50-51).

A instalação da Corte Portuguesa no Brasil, no início do século XIX, lança o país a um novo status político e social, que reverbera na questão educacional de sobremaneira, posto que

\begin{abstract}
depois da elevação do reino do Brasil, os brasileiros passaram a ter o dever de dar aos filhos, não somente a educação moral e a instrução moral e a instrução primária ou científica necessárias a todos os homens (uma obrigação) mas também o de lhes inculcar, por assim dizer, na alma nacional, este sentimento de fraternidade para com todos os homens do próprio país, que fez a força da nação e assegurou sua independência. (ALMEIDA 2000, p. 51).
\end{abstract}

A insistência de Almeida em provar a superioridade brasileira no campo educacional quando comparada - em especial -, com a Argentina, o leva a tecer argumentos peculiares e que dão o tom do pensamento político e social do autor. Por exemplo, ao informar que oficialmente cerca de $6 \%$ da população total da Argentina estava na escola e que, no Brasil, o percentual da população total que frequentava a escola era de aproximadamente $2 \%$ ao final do século XIX, Almeida recorre aos dados brutos da estimativa populacional brasileira à época para ponderar que "nesta cifra da população estão incluídos os indígenas e os trabalhadores rurais da raça africana" (ALMEIDA, 2000, p.18), sendo que para uma comparação justa, na visão do autor, seria necessário refazer o cálculo e "reduzir mais da metade da população do Império, a fim de se determinar, com segurança, os cálculos estatísticos, porque, talvez, não haja seis milhões de habitantes aptos para frequentar as escolas primárias públicas ou privadas" (ALMEIDA, 2000, p.18, grifos nossos).

A quinta e última abordagem em relevo na nossa análise diz respeito às potenciais contribuições da obra de José Ricardo Pires de Almeida para discussões acerca da história da educação brasileira. Nessa abordagem, são especialmente instigantes temas como a sistematização de informações realizada pelo autor, suas 
análises políticas e pedagógicas sobre temas como o ensino mútuo e a escola mista e o financiamento da educação.

O texto todo é bastante assinalado pela presença de informações quantitativas, que emprestam um caráter de cientificidade à narrativa, mas também auxiliam de forma clara a reconstituição de contextos da educação brasileira ao longo da história. Por exemplo, no segundo quartel do século XIX havia, em todo o Império

\begin{abstract}
162 escolas de meninos e 18 de meninas; estas escolas estavam estabelecidas no Rio de Janeiro e na província do mesmo nome e também nas províncias da Bahia, Pernambuco, Rio Grande do Norte, Piauí, Pará, Mato Grosso, Goiás e S. Pedro do Rio Grande do Sul; sobre estas 180 escolas, havia ao menos 40 nas quais o lugar do professor estava vacante, e deste número, 8 eram escolas de meninas. Havia, pois, em todo o Brasil, 10 escolas para o sexo feminino (ALMEIDA, 2000, p. 61)
\end{abstract}

O autor parece muito seguro para elaborar suas afirmações, especialmente, quando é possível pautá-las em números e subsídios quantificáveis. Por exemplo: apresenta tabelas com nações, anos, despesas (com educação) e população, para após fazer comparações e tirar conclusões. Apresenta, ainda, tabelas e relatórios, indicando fontes oficiais, para na sequência desenvolver sua narrativa. Além do que, a exposição consciente de dados, fatos, legislações e relatórios deixam antever um historiador que ocupa-se também da pesquisa, emprestando credibilidade aparente aos seus escritos. Todavia, é lícito informar que Almeida, além de médico, também fora arquivista da Câmara Municipal do Rio de Janeiro e da Inspetoria Geral de Higiene, portanto, tinha conhecimento acerca dos procedimentos de guarda e catalogação de informações e levantamento documental (informação capturada do site: http://www.literaturabrasileira.ufsc.br/autores/?id=4420).

No que concerne às suas análises sobre temas como o ensino mútuo e a escola mista, o autor dá sinais de um certo pensamento crítico ao verificar, em relação ao primeiro tema, sua plausibilidade ante à questão econômica, uma vez é compreensível a preferência legal "pelo método de ensino mútuo, quando se sabe que, por este sistema, duzentas, trezentas crianças ou mais podem receber a instrução primária suficiente, sem que haja necessidade de mais que dois ou três professores" (ALMEIDA, 2000, p. 60).

Em relação ao segundo tema, Almeida destaca que "a instrução das mulheres era nula ou quase nula e, doutra feita, os hábitos e costumes quase não permitiam à mulher 
exercer uma função pública" (ALMEIDA, 2000, p. 61). Diante dessa lacuna, a escola mista apresentava-se como uma opção interessante, uma vez que

\begin{abstract}
no país onde o sistema misto é comum, seu público reconhece as seguintes vantagens: $1^{\circ}$ ) grande comodidade para os pais que enviam seus filhos juntos para um mesmo estabelecimento e não para dois diferentes, situados às vezes longe um do outro; $2^{\circ}$ ) continuação da vida familiar para os irmãos e irmãs reunidos em uma mesma escola; $3^{\circ}$ ) emulação maior entre as crianças; $4^{\circ}$ ) aquisição de bons hábitos desde a primeira juventude, tanto para os meninos quanto para as meninas; $5^{\circ}$ os fatos que se quer prevenir, pela segregação dos sexos e a vigilância incessante, são muito mais raros nos países onde a educação é dada em comum do que naqueles onde o sistema misto não existe. (ALMEIDA, 2000, p. 154).
\end{abstract}

Outro ponto que merece a atenção do autor é o tema 'financiamento da educação'. Em relação aos investimentos públicos, o autor reivindica que venham acompanhados de um princípio de eficiência e desempenho, considerando a relação entre o investimento e os resultados obtidos:

É, entretanto, incontestável que, comparando a população com o número de crianças inscritas nas escolas, o ensino primário no Brasil está em desacordo com a escala que ocupa entre os povos cultos. Com efeito, as quantias despendidas com a instrução pública no município e nas províncias deveriam produzir resultados mais positivos (ALMEIDA, 2000, p.296).

Todavia, em vários momentos, o autor também mostra que o investimento brasileiro em instrução pública é precário e está aquém dos dados da Argentina. O interessante é que para equacionar tal defasagem o autor não propõe um aumento do investimento, mas sim um novo cálculo, que exclua da contagem populacional (para correlação população $X$ investimento) determinados grupos sociais supostamente nãoaptos da educação escolarizada (ALMEIDA, 2000, p. 18).

Com essas ênfases, Almeida é abertamente um historiador da história política. Dos números, dados e fatos, reivindica a si e aos seus escritos uma condição de ciência historiográfica bem ao gosto da época na qual vive e realiza sua empreitada narrativa.

Mesmo não sendo um historiador de formação acadêmica, Pires de Almeida resta por produzir, em razão da história da educação, uma narrativa indexada ao ofício de historiador, deixando patente seu lugar de fala (que em momento algum é camuflado), mostrando um estilo próprio de conduzir a narrativa, estilo que perpassa a forma e o conteúdo "entrelaçados para formar a tessitura de toda arte e todo o ofício e também a história" (GAY, 1990, p. 17). 


\section{Conclusão...}

O texto procurou focar na produção de interpretações da história, realizada por José Ricardo Pires de Almeida, enquanto historiador que narra a educação brasileira, a partir da análise da obra L'Instruction publique au Brésil: histoire et legislation (15001889) em sua tradução para o português.

A história da educação é considerada um campo híbrido, sendo "ao mesmo tempo uma subárea da educação e uma especialização da história" (VIDAL; FARIA FILHO, 2003, p.60) e, talvez em razão de tal condição, aceita com relativa indiferença a presença de narradores de diversas áreas do conhecimento, como no caso do autor em estudo.

Tal abordagem leva em conta a produção da história e da história da educação, por consequência, como produções dinâmicas, que partem de distintas fontes e levam em consideração os tempos e os lugares de fala dos sujeitos que as produzem, pois "não se explica um fenômeno histórico fora do estudo de seu movimento" (BLOCH, 2001, p.60).

Dessa forma, centramos análises em cinco abordagens evidenciadas pelo autor através de sua obra: o tom ufanista com o qual desenvolve uma narrativa pretensamente científica e linear; a perspectiva imperial ou sua aderência explícita à monarquia como regime de governo; o dualismo escolar presente na narrativa; a perspectiva de história comparada ou a necessidade de constantes comparações e, por fim, as contribuições pontuais da obra de José Ricardo Pires de Almeida para a história da educação brasileira.

À luz do presente, a obra de Pires de Almeida pode ser objeto de diversas e variadas críticas, uma vez que

\footnotetext{
Pires de Almeida, apesar do esforço para se manter dentro do ideal do comportamento do historiador metódico e fiel aos fatos e à verdade, [em] sua escrita evidencia explícita e frequentemente os seus juízos de valor motivados claramente pela sua ideologia política, crença religiosa, preconceitos raciais e pela soberba de elite culta, em um país em que a imensa maioria da população não tinha acesso sequer à educação primária (VIEIRA, 2015, p.767)
}

Todavia, o lugar de fala de Almeida o coloca como filho do seu tempo e contexto histórico, sendo que sua proposta de trabalho é eivada pelo pensamento comum dominante, mais compromissado em afirmar ideias através dos espaços de 
socialização (no caso, o livro), do que com a inovação pedagógica ou a emancipação social.

Apesar desse compromisso indexado, claramente assumido e de fácil percepção a qualquer leitor, a obra tem méritos evidentes e, o maior de todos, sistematiza informações acerca da história da educação brasileira, fato pioneiro no período e na abrangência da narrativa.

\section{REFERÊNCIAS BIBLIOGRÁFICAS:}

ALMEIDA, José Ricardo Pires de; GUEDES, Maria do Carmo (Coord.). Instrução pública no Brasil (1500-1889): história e legislação. 2. ed. São Paulo: Ed. Pontifícia Universidade Católica de São Paulo, 2000. 334 p.

BARDIN, Laurence. Análise de Conteúdo. Trad. Luiz Antero Reto e Augusto Pinheiro. Lisboa: Edições 70, 2007.

BLOCH, Marc. Apologia da História, ou, O Ofício de Historiador. Edição anotada por Étienne Bloch. Prefácio de Jacques Le Goff. Apresentação à edição brasileira de Lilia Moritz Schwarcz. Tradução de André Telles. Rio de Janeiro: Zahar Ed., 2001.

CERTEAU, Michel de. A operação historiográfica. In: A escrita da história. 3. ed. Tradução de Maria de Lourdes Menezes. Revisão técnica de Arno Vogel. Rio de Janeiro: Forense Universitária, 2011.

FELGUEIRAS, Margarida de Louro. A história da educação na relação com os saberes histórico e pedagógico. Revista Brasileira de Educação. v. 13 n. 39 set./dez. 2008, p. 483-501.

GAY, Peter. O estilo na história. Trad: Denise Bottman. São Paulo: Companhia das Letras, 1990.

GONDRA, José. Instrução pública no Brasil (1500-1889). Revista Brasileira de História da Educação, Rio de Janeiro, n. 14, p. 189-191, Aug. 2000.

José Ricardo Pires de Almeida. In: BRITTO, Jader de Medeiros; FÁVERO, Maria de Lourdes de Albuquerque (Orgs.). Dicionário dos educadores no Brasil: da Colônia aos dias atuais. Rio de Janeiro: Editora UFRJ, 2003. p. 643-647.

LE GOFF, Jacques. História e memória. Tradução de Bernardo Leitão et. al. $5^{\text {a }}$ ed. Campinas, SP: Editora da UNICAMP, 2003.

NÓVOA, António. Para que a História da Educação? In: STEPHANOU, Maria; BASTOS, Maria Helena Camara (orgs.). Histórias e Memórias da Educação no Brasil. Vol. I. Petrópolis, RJ: Vozes, 2004

SAVIANI, Dermeval. A produção em história da educação na pós-graduação. InterMeio: revista do Programa de Pós-Graduação em Educação, Campo Grande, MS, v.15, n.29, p.235-251, jan./jun. 2009. 
VIDAL, Diana Gonçalves; FARIA FILHO, Luciano Mendes de. História da educação no Brasil: a constituição histórica do campo (1880-1970). Revista Brasileira de História, São Paulo, v. 23, n. 45, p. 37-70, Jul 2003.

VIEIRA, Carlos Eduardo. José Ricardo Pires de Almeida entre duas vocações: a política e a ciência. Cadernos de História da Educação - v. 14, n. 3 - set./dez. 2015, p. 753771.

TAMBARA, Elomar. Problemas Teórico-metodológicos da História da Educação. In: História e História da Educação. Campinas, SP: Autores Associados: HISTEDBR, 2000 . 